\title{
A EXPLORAÇÃ̃ ECONÔMICA DE BENS PÚBLICOS POR MEIO DA CESSÃO ONEROSA DE NAMING RIGHTS
}

\author{
André Dias Fernandes \\ Centro Universitário 7 de Setembro (UNI7), Ceará \\ andredias@uni7.edu.br \\ Letícia Queiroz Nascimento \\ Centro Universitário 7 de Setembro (UNI7), Ceará \\ leticiaqnascimento@gmail.com
}

\begin{abstract}
RESUMO: O presente artigo analisa a possibilidade jurídica de exploração econômica de bens públicos mediante cessão onerosa do direito de denominação. Para tanto, a metodologia utilizada foi qualitativa e teórica, com emprego dos métodos indutivo e comparativo, uma vez que foram analisados casos concretos de cessão onerosa de naming rights de bens públicos, especialmente da experiência estrangeira. No primeiro tópico, analisa-se a forma de gerenciamento de bens públicos em um novo contexto da Administração Pública, considerando o princípio da eficiência e a funcionalidade dos bens públicos. Posteriormente, contextualiza-se a questão da comercialização dos naming rights para fins publicitários. No terceiro tópico, reflete-se acerca da viabilidade de utilização da cessão onerosa de naming rights como forma de exploração de bens públicos, observando a sua compatibilidade com as normas do direito brasileiro. Conclui-se, por fim, ser possível a aplicação dos naming rights como meio de exploração econômica de bens públicos no Brasil, em que pese a inexistência de autorização legislativa expressa para sua realização, desde que observados alguns limites e parâmetros.
\end{abstract}

PALAVRAS-CHAVE: Naming Rights. Bens públicos. Direito de denominação.

The economic exploitation of public goods through the onerous assignment of naming rights

ABSTRACT: This article analyzes the legal possibility of economic exploitation of public goods through the onerous assignment of the right of denomination. To this end, the methodology used was qualitative and theoretical, with the use of inductive and comparative methods, since specific cases regarding naming rights about public goods were analyzed, especially from foreign experience. In the first topic, the way of managing public goods in a new context of Public Administration is analyzed, considering the principle of efficiency and the functionality of public goods. Subsequently, the question of the commercialization of naming rights for advertising purposes is contextualized. In the third topic, we reflect on the feasibility of using naming rights contracts as a way of exploiting public goods, observing their compatibility with the rules of Brazilian law. Finally, it is concluded that it is possible to apply naming rights as a means of economic exploitation of public goods in Brazil, despite the lack of express legislative authorization for their implementation, provided that certain limits and parameters are observed.

KEYWORDS: Naming Rights. Public goods. Right of denomination. 


\section{INTRODUÇÃO}

Nas últimas décadas, o modelo organizacional da Administração Pública gerencial, norteado por valores como a eficácia e a eficiência, ganhou força no cenário mundial e suas propostas têm adquirido cada vez mais espaço na gestão pública de diversos países, inclusive no Brasil.

Dentre as transformações ocorridas na Administração Pública, é possível identificar a incorporação de práticas advindas do setor privado e o aumento de administradores gestores, com maior autonomia para decidir, a viabilizar um melhor desempenho da gestão pública e uma modificação da relação entre administradores e administrados.

Paralelamente, em decorrência do desafio de satisfação de necessidades sociais cada vez mais variadas na sociedade "hipermoderna" (Lipovetsky, 2004, passim), em perene e acelerada mutação, há um paulatino incremento dos encargos estatais, particularmente tormentosos em quadras de recessão econômica como a atualmente vivenciada no Brasil, conduzindo o Estado à busca de meios alternativos para obtenção de capital com o objetivo de atender às múltiplas demandas sociais.

Dessarte, diante da dificuldade financeira da Administração Pública de atender aos seus muitos compromissos e da inviabilidade de aumento da carga tributária, identifica-se a necessidade de novas fontes de renda pública. É nesse contexto, associado ao movimento de aproveitamento de institutos da administração privada no âmbito da Administração Pública, que se cogita a possibilidade de exploração econômica de bens públicos para fazer face à insuficiência de recursos, sem aumentar a carga tributária.

Os bens públicos, dotados de potencialidade econômica, podem ser utilizados como instrumentos de captação de recursos oriundos da esfera privada, que, por sua vez, podem ser convertidos em benefícios para a sociedade ou para os próprios bens. Assim, é possível que estes bens sejam mais bem geridos e que eventuais ganhos auferidos possam ser revertidos para a Administração Pública, observando o princípio da eficiência e a funcionalidade dos bens públi$\cos$.

Inspirado na comercialização de naming rights, prática empresarial norte-americana, o Brasil passou a levar a efeito, ainda que de maneira tímida no âmbito das relações privadas, a exploração econômica de bens mediante a cessão onerosa dos direitos de denominação, ativos intangíveis que provaram ser economicamente relevantes.

Este tema cobra relevo com a previsão e disciplina de naming rights no anteprojeto de lei do "Programa Universidades e Institutos Empreendedores e Inovadores - Future-se" submetido a consulta pública em janeiro de 2020. Após intenso debate público, foi finalmente enviado à Câmara dos Deputados o respectivo Projeto de Lei (PL n. 3076/2020), preservando, na essência, a disciplina de naming rights constante do anteprojeto.

O objetivo deste trabalho é debater a viabilidade jurídica de exploração econômica de bens públicos por meio da cessão onerosa do direito de denominação como fonte alternativa de arrecadação de recursos monetários para a Administração Pública brasileira.

Assim, a partir da análise da experiência estrangeira com a cessão onerosa de naming rights de espaços sociais e instituições públicas, questiona-se acerca da possibilidade de utilização desse instituto de origem norte-americana no Brasil e sobre as controvérsias daí derivantes, assim como em relação aos limites impostos pelo ordenamento jurídico brasileiro.

Isto posto, a metodologia utilizada será qualitativa e teórica, uma vez que serão exploradas referências bibliográficas de livros, artigos periódicos e notícias acerca do tema. Ademais, 
serão mobilizados os métodos indutivo e comparativo, dado que serão observados casos concretos em que foi utilizada a cessão onerosa do direito de denominação de bens públicos.

Este texto está dividido em três tópicos. Inicialmente, procede-se a uma análise da forma de gestão de bens públicos no Brasil em um novo contexto da Administração Pública, considerando o princípio da eficiência e a funcionalidade dos bens públicos. Posteriormente, é contextualizada a questão da comercialização dos naming rights para fins publicitários, utilizando exemplos da experiência estrangeira em relação ao referido instituto. Por fim, são apresentadas reflexões acerca da viabilidade da cessão onerosa de naming rights como forma de exploração de bens públicos, sendo observada a compatibilidade com as normas do direito brasileiro.

\section{O GERENCIAMENTO DE BENS PÚBLICOS NO BRASIL E O PRINCÍ- PIO DA EFICIÊNCIA}

Em um cenário onde se vê a necessidade de ampliação de receitas públicas, verifica-se a imprescindibilidade de busca por fontes alternativas de captação de recursos, visto que as necessidades da população crescem além da capacidade de arrecadar dos entes estatais, e os bens públicos podem ser convocados a colaborar para este desiderato.

Antes de estabelecer a possibilidade de utilização da cessão onerosa de naming rights para bens públicos como solução, ainda que parcial, para a insuficiência de recursos financeiros, convém melhor compreender como os bens públicos são geridos no Brasil, bem como verificar a sua classificação estabelecida pelo Código Civil.

Existem dois principais critérios utilizados para identificação de um bem público, sendo o primeiro deles relativo à titularidade do bem. Segundo este fundamento, bens públicos são aqueles cuja titularidade é de um sujeito dotado de personalidade jurídica de direito público. O segundo critério é em relação ao regime jurídico aplicável, sendo os bens públicos aqueles subordinados ao regime de direito público (JUSTEN FILHO, 2015, p. 217).

O Código Civil brasileiro define em seu art. 98 que bens públicos são aqueles “do domínio nacional pertencente às pessoas jurídicas de direito público interno; todos os outros são particulares, seja qual for a pessoa a que pertencem". No seu art. 99, classifica os bens públicos em: a) bens de uso comum do povo, tais como rios, mares, estradas, ruas e praças; b) bens de uso especial, como edifícios ou terrenos destinados a serviços ou estabelecimento da administração federal, estadual, territorial ou municipal, inclusive os de suas autarquias; e c) bens dominicais, que constituem o patrimônio das pessoas jurídicas de direito público a que se tenha dado estrutura de direito privado. ${ }^{1}$

Verifica-se, mediante a classificação estabelecida pelo Código Civil, que os bens de uso comum do povo e de uso especial são inalienáveis, portanto, não podem ser vendidos ou cedidos, sendo, porém, tal inalienabilidade condicionada à conservação de sua qualificação, consoante prescreve art. 100 do CC/2002. Presume-se, portanto, que desde que não haja modificação do seu estado enquanto bem público, é possível que tal bem possa ser gerenciado pelo ente estatal e instrumentalizado para que atenda às necessidades da Administração Pública.

Os bens dominicais, por outro lado, são alienáveis, devendo ser observadas as disposições da Lei 8.666/93, que determinam os requisitos para sua alienação. Segundo o disposto nos artigos

\footnotetext{
1 Ressalte-se ainda a existência das terras indígenas que são consideradas bens públicos por força do art. $231 \S 4^{\circ}$, da Constituição Federal de 1988, que determina que estas são "inalienáveis, indisponíveis, e os direitos sobre elas, imprescritíveis”. Entretanto, não se encaixam na classificação proposta pelo Código Civil Brasileiro.
} 
17 a 19 da referida lei, é possível a alienação dos bens públicos dominicais mediante interesse público devidamente justificado, autorização legislativa, avaliação prévia e licitação nas modalidades de concorrência ou leilão, salvo situações excepcionais.

É possível perceber que o legislador civil estabeleceu uma classificação distinta para os bens públicos, conferindo-lhes, conforme apresentado, tratamento e regimes jurídicos próprios. Entretanto, o ponto de convergência entre as categorias que merece ser ressaltado é que todos possuem uma função para a sociedade.

Ikenaga (2012, p. 8) afirma que, para analisar a possibilidade de exploração econômica de bens públicos, é preciso entender que, independentemente de classificação, os bens públicos são dotados de funcionalidade pública.

Quanto à possibilidade de exploração econômica dos bens públicos, verifica-se que estes, por via de regra, possuem amplo alcance e visibilidade, o que lhes confere alta potencialidade econômica, e são considerados atrativos para que investidores (empresas privadas ou pessoas físicas) possam aplicar o seu capital nestes bens.

O direito de denominação de bens públicos, por exemplo, pode ser inserido na categoria de ativos intangíveis. Para Hoss (2008), ativos intangíveis são incorpóreos e podem ser representados por bens e direitos associados a uma organização e, independentemente de estarem contabilizados, possuem valor e podem agregar vantagens competitivas, tal como é o caso de uma marca. Portanto, são passíveis de exploração econômica e de produção de vantagens financeiras que podem ser utilizadas em benefício do próprio bem ou para os administrados, sem que o bem venha a ser deteriorado ou perca a sua funcionalidade pública.

Além do alcance a um grande número de pessoas e da visibilidade que o bem público costuma possuir, o adquirente do direito de denominação pode ser beneficiado por uma publicidade gratuita indireta, visto que é bastante comum que bens e espaços públicos tenham seus nomes divulgados em meios de comunicação e mídias sociais. Assim, quando um veículo de comunicação citar o bem público, mencionará o nome do investidor que adquiriu o direito de denominação.

Assim, pelo menos a princípio, não haveria razão para que a Administração Pública não pudesse (ou até mesmo devesse) utilizar a já mencionada potencialidade econômica dos bens públicos e de seus ativos intangíveis, e explorá-los economicamente para que os bens públicos possam efetivamente exercer, da maneira mais plena possível, suas funcionalidades em prol dos administrados.

Desta maneira, entende-se que os bens públicos possuem o importante papel de instrumento de satisfação de demandas sociais, enquanto a administração, agindo de modo eficiente e voltado à funcionalidade pública, deve dar plena utilidade ao espaço público, evitando condutas (ativas ou omissivas) que não atendam sua função social (ALMEIDA, 2013, p. 4).

Trata-se, pois, de instrumentalização adequada dos bens públicos. Exige-se cada vez mais eficiência dos administradores, que podem (e devem) utilizar toda a potencialidade econômica dos bens públicos como ferramenta para o cumprimento dos encargos estatais.

Afastando-se (mas não rompendo) cada vez mais do modelo burocrático, o Brasil gradativamente se apropria do modelo gerencial da Administração Pública, que pode ser definido como um modelo pós-burocrático para a estruturação e a gestão da Administração Pública baseado em valores de eficiência, eficácia e competitividade (SECCHI, 2009, p. 354). 
A nova fase vivida pela Administração Pública se distancia do modelo burocrático e guarda aspectos do gerencialismo, ancorando o seu modelo organizacional no princípio da eficiência. Este princípio foi elevado ao status constitucional pela Emenda Constitucional no 19/98, de maneira que a Administração Pública direta ou indireta deve obedecer aos princípios de legalidade, impessoalidade, moralidade, publicidade e eficiência.

Di Pietro (2017, p. 115) assevera que o princípio da eficiência deve somar-se aos demais princípios impostos à Administração, não podendo sobrepor-se a nenhum deles, especialmente ao da legalidade, sob pena de colocar-se em risco a segurança jurídica e o próprio Estado de Direito.

Nesse sentido, questiona-se acerca dos limites ao princípio da eficiência. É necessário ponderar a sua aplicação, uma vez que um princípio, teoricamente, não pode servir de "carta branca" para que os agentes da Administração Pública possam agir com a liberdade da autonomia da vontade comum às relações privadas. Ademais, conforme mencionado, a Administração Pública deve obedecer tanto ao princípio da eficiência, como ao da legalidade.

Critica-se, por vezes, tamanha liberdade em razão da indisponibilidade do interesse público, salientando-se que, no direito administrativo brasileiro, disposições constitucionais genéricas conferem aos agentes administrativos a possibilidade de justificar virtualmente qualquer tipo de ação (SCHIRATO, 2011, p. 138).

Além disso, nenhum órgão público se tornará mais eficiente em razão de a eficiência ter sido elevada a princípio constitucional, sendo preciso que se mude a mentalidade dos governantes e gestores, que devem agir em busca dos interesses reais da coletividade e não de seus interesses pessoais (CARVALHO FILHO, 2019, p. 31).

De qualquer sorte, à vista da necessidade de captação de recursos financeiros adicionais, vitais em períodos de crise econômica, e da evolução da Administração Pública que aos poucos se desvencilha do burocratismo, revela-se insensata a perda de oportunidades de arrecadação por meio de bens públicos que podem atender a fins de maior relevância para os administrados.

Assim sendo, a cessão onerosa dos direitos de denominação de bens públicos como forma de obtenção de benefícios econômicos, sejam eles de natureza pecuniária ou não, é um exemplo concreto da mudança pela qual a Administração Pública vem passando nos últimos anos, utilizando institutos mais eficientes advindos da iniciativa privada.

\section{NAMING RIGHTS: A CESSÃO ONEROSA DO DIREITO DE DENOMINA- ÇÃO}

De início, cumpre ressaltar que a tradução literal da locução americana "naming rights" para o vernáculo gera alguns inconvenientes, uma vez que expressões como "direito ao nome" ou "direito à nomeação" já são empregadas em alguns ramos do direito com significados específicos, relacionados aos direitos da personalidade ou a cargos públicos, por exemplo. Assim, alguns autores preferem aludir a "direito de denominação" (ou "direito à denominação") ou a "atribuição de nome" ao tratar dos naming rights.

A cessão onerosa de naming rights teve seus primeiros registros no início do século XX nos Estados Unidos, num cenário em que clubes de esporte que necessitavam de novas fontes de recursos financeiros passaram a ceder o direito de denominação de suas arenas esportivas em troca de investimentos de empresas privadas, difundindo-se a prática ao redor do mundo (TREX, 2008). 
A exploração econômica de bens públicos por meio da cessão onerosa de naming rights

A atribuição de um nome permite a conceitualização dos sujeitos e dos objetos, possuindo as funções de identificação do sujeito ou do objeto nomeado, e, por conseguinte, exerce o papel de diferenciá-los entre si. Além disso, pode apresentar - mas não necessariamente - uma função de personificação, de modo que o nome deixa de ser algo externo ao sujeito, tornando-se indissociável de sua própria existência. Desempenhando tais funções, os nomes adquirem relevância econômica, de modo que as escolhas dos consumidores passam a ser influenciadas pela imagem associada aos nomes (JUSTEN FILHO, 2015, p. 222).

Assim, é possível reconhecer que os nomes possuem relevância econômica para as atividades empresariais, e, por consequência, ensejam a possibilidade de auferir renda a partir da exploração do correlato direito de nomear. A partir dessa perspectiva, especialmente no cenário internacional, iniciou-se a prática empresarial de cessão onerosa do direito à denominação de uma atividade ou um edifício para fins publicitários.

Define-se a comercialização do direito de denominação como sendo um negócio jurídico pelo qual uma pessoa física ou jurídica adquire o direito de denominar um determinado equipamento ou evento, público ou privado, durante determinado período, mediante uma contraprestação pecuniária (URBANO, 2013, p. 4).

Verificou-se que a cessão onerosa do direito de denominação acarretava uma visibilidade significativa para o adquirente, reforçando o entendimento de que a nomeação é relevante economicamente, passando a ser compreendida como um ativo intangível.

É importante destacar que a cessão onerosa de naming rights apenas confere ao adquirente o direito de nomeação, de modo que a propriedade permanece sendo do titular do bem. Portanto, ainda que uma pessoa ou empresa obtenha o referido direito, não poderá alienar e dispor da propriedade, já que este negócio jurídico não atinge a titularidade do bem.

Quanto ao período de cessão do direito de denominação, cumpre destacar que, atualmente, os contratos de naming rights são normalmente celebrados por prazo determinado, mesmo porque é importante que o titular do bem não perca de forma definitiva o direito de nomear livremente, visto que esta é uma prerrogativa inerente à propriedade. Embora nos primórdios da experiência norte-americana se deparem vários casos de cessão permanente do direito à denominação em relação a bens privados (e ainda hoje se celebrem contratos de cessão permanente $^{2}$, malgrado a tendência de predomínio das cessões temporárias), tal perpetuidade seria dificilmente compaginável com o regime jurídico dos bens públicos no ordenamento brasileiro.

Com efeito, mesmo no que diz com bens privados, verificou-se que a perpetuidade da cessão seria, por via de regra, inconveniente, por privar definitivamente o proprietário do bem da possibilidade de celebrar novos contratos de naming rights, reduzindo as receitas potencialmente daí advindas. Mister é de ressaltar que o valor de tais cessões onerosas tem aumentado exponencialmente nas últimas décadas ${ }^{3}$, de maneira que os custos de oportunidade ${ }^{4}$ decorrentes

2 "If the named gift was for an endowment in perpetuity then there are no restrictions on the length of term. As in the example of the endowed chairs set up at Oxford and Harvard hundreds of years ago, they both still exist today." (BURTON, 2008, p. 163).

3 Acerca da escalada dos valores dos contratos de naming rights, cf. BURTON, 2008, p. 1-48.

4 "When economists refer to the 'opportunity cost' of a resource, they mean the value of the next-highest-valued alternative use of that resource. If, for example, you spend time and money going to a movie, you cannot spend that time at home reading a book, and you cannot spend the money on something else. If your next-best alternative to seeing the movie is reading the book, then the opportunity cost of seeing the movie is the money spent plus the pleasure you forgo by not reading the book. [...] This simple concept has powerful implications. It implies, for example, that even when governments subsidize college education, most students still pay more than half of the cost. Take a student who annually pays $\$ 4,000$ in tuition at a state college. Assume that the government subsidy to the college amounts to $\$ 8,000$ per student. It looks as if the cost is $\$ 12,000$ and the student pays less than half. But looks can be deceiving. 
da perenidade da cessão seriam muito elevados. No caso dos bens públicos, além de razões econômicas, há ainda aspectos morais, republicanos e jurídicos por ponderar, uma vez que a perpetuidade da cessão magnifica e acentua a impressão de privatização do bem público, além de suprimir da Administração e da sociedade o direito de rever periodicamente as escolhas feitas à luz do sempre cambiante interesse público. ${ }^{5}$

Portanto, no que entende com naming rights sobre bens públicos, o caráter transiente do contrato é inarredável no direito pátrio.

Em relação à natureza do bem cujos ativos serão objeto do negócio jurídico, é importante que haja compatibilidade entre o bem e o adquirente que irá usufruir do direito de denominação, especialmente quando se trata do direito de denominação de bens públicos, como será melhor abordado no terceiro tópico deste trabalho.

A comercialização dos naming rights é comumente utilizada para a denominação de arenas e eventos esportivos, entretanto não há restrição para adotar a prática em outros espaços, cujos ativos são relevantes economicamente e são capazes de auferir ganhos econômicos para bens como hospitais, escolas, estações de transporte coletivo etc.

É evidente, portanto, a potencialidade econômica do instituto da cessão onerosa do direito de denominação como meio alternativo de arrecadação de recursos financeiros. Não se pode olvidar, entretanto, que não existem apenas aspectos positivos em nenhuma forma de transação empresarial, de modo que não poderia ser diferente com a comercialização de naming rights.

Para que o Brasil possa exercer com habilidade a prática empresarial que envolve os direitos de denominação, convém extrair lições de casos concretos da experiência estrangeira, considerando todos os aspectos, inclusive os possíveis riscos advindos da atividade. Dessa forma, é possível que o ordenamento jurídico brasileiro possa aperfeiçoar o instituto jurídico e se resguardar de eventuais adversidades, corrigindo erros do passado e adaptando a atividade às normas brasileiras.

Nesse contexto, quadra mencionar o caso da empresa Enron Corporation, apontado pela doutrina como exemplo paradigmático de experiência negativa de contratação de naming rights de estádio esportivo. A empresa de energia, commodities e serviços dos Estados Unidos adquiriu o direito de denominação de um estádio de beisebol por 100 milhões de dólares pelo prazo de trinta anos; entretanto, dois anos após a contratação, em razão de escândalos de contabilidade (JORNAL CONTÁBIL, 2018), o estádio comprou de volta o direito de denominação por 2,1 milhões de dólares (ISIDORE, 2002).

Trata-se de um exemplo clássico de cessão de naming rights malsucedida, que ocasionou uma publicidade negativa para o bem em razão de um escândalo envolvendo a empresa investidora, evidenciando a associação inevitável entre os envolvidos no negócio jurídico.

The true cost is $\$ 12,000$ plus the income the student forgoes by attending school rather than working. If the student could have earned $\$ 20,000$ per year, then the true cost of the year's schooling is $\$ 12,000$ plus $\$ 20,000$, for a total of $\$ 32,000$. Of this $\$ 32,000$ total, the student pays $\$ 24,000$ ( $\$ 4,000$ in tuition plus $\$ 20,000$ in forgone earnings). In other words, even with a hefty state subsidy, the student pays 75 percent of the whole cost. This explains why college students at state universities, even though they may grouse when the state government raises tuitions by, say, 10 percent, do not desert college in droves. A 10 percent increase in a $\$ 4,000$ tuition is only $\$ 400$, which is less than a 2 percent increase in the student's overall cost". (HENDERSON, 2006).

5 Consoante Luis Felipe Sampaio (SAMPAIO, 2017, p. 147), contratos perpétuos de naming rights sobre bens públicos são juridicamente possíveis, mas devem ser evitados. Já para Marçal Justen Filho, “a cessão deverá ser temporária, por prazo determinado. Não caberá promover a cessão definitiva e permanente da denominação do bem público precisamente porque isso configuraria uma forma de alienação do dito cujo." (JUSTEN FILHO, 2015, p. 237). 
A exploração econômica de bens públicos por meio da cessão onerosa de naming rights

Ressalte-se que o início da prática de utilização dos naming rights se deu nos Estados Unidos, onde eram comuns manifestações de agradecimento por doações de recursos para obras e atividades filantrópicas, que nomeavam as suas instituições em homenagem aos doadores. No entanto, nestes casos não havia contraprestação pecuniária, mas somente a nomeação honorífica.

Portanto, quando o adquirente do direito de nomeação é pessoa física, é comum que cause confusão entre a população de um modo geral, que pode acabar por confundir a aquisição deste direito com a nomeação honrosa.

No Brasil, a comercialização do direito de denominação ainda é figura pouco conhecida e explorada de maneira tímida pelos empresários para fins publicitários, mas tem crescido no que respeita a arenas esportivas, como, por exemplo, a Kyocera Arena, do Clube Atlético Paranaense ${ }^{6}$, e o Allianz Parque, do Clube do Palmeiras.

Em razão do crescimento da prática empresarial entre os particulares, esta atividade rapidamente se expandiu para a iniciativa pública em alguns países. Atualmente, é comum nos EUA e em alguns países europeus que prédios públicos, instituições de ensino, bibliotecas e parques públicos utilizem a cessão onerosa de naming rights como meio de captação de recursos e superação de eventuais dificuldades financeiras do Estado.

No âmbito público brasileiro, poucos são os exemplos que podem ser citados, como o edital de concessão de uso da Pedreira Paulo Leminski, no município de Curitiba, que abria a possibilidade de concessão de uso da pedreira, incluindo o seu direito de denominação. Contudo, não houve boa aceitação pela população, que não se sentiu contemplada pela iniciativa municipal, sendo um modelo ineficiente de exploração econômica de bens públicos, dado que não atendeu aos interesses dos administrados. ${ }^{7}$

No contexto internacional, na cidade de Dubai, por exemplo, foi franqueada a aquisição onerosa do direito de denominação de estações metroviárias por parte de empresas privadas. $\mathrm{O}$ objetivo do projeto, lançado em 2012, foi a arrecadação de recursos, que permitiram a elevação da qualidade do serviço de transportes públicos, trazendo reais benefícios para os usuários desse serviço.

A comercialização de naming rights gradativamente passou a ser inserida nas práticas dos agentes públicos e ter maior relevância para a população da cidade. Em 2019, a empresa de refrigerantes Coca-Cola assinou um contrato de dez anos com a Arena esportiva de Dubai, possibilitando a construção da maior área coberta da região do Oriente Médio e Norte da África (HALLIGAN, 2019).

Percebe-se que vários são os requisitos que devem ser observados para que seja legitimamente efetuada a cessão dos direitos de denominação de bens públicos, levando-se em conta não somente a instrumentalização do bem como fonte de captação de recursos, mas, outrossim, a necessidade de participação popular, a corroborar a efetiva existência de interesse público na cessão e a conferir legitimidade ao instituto.

Diante dos casos apresentados, é absolutamente necessária a análise da cessão onerosa de naming rights em países onde a prática está mais bem desenvolvida, para que seja possível a adequação e aprimoramento do instituto norte-americano ao ordenamento jurídico brasileiro, caso contrário a expansão da prática no Brasil pode ocasionar prejuízos, seja nas relações entre particulares, seja no âmbito da Administração Pública.

6 Disponível em: http://jcrs.uol.com.br/noticias.aspx?pCodigoNoticia=10908\&pCodigoArea=40. Acesso em: 15 jul. 2019.

7 Disponível em: https://www.cmc.pr.gov.br/anexo.php?anexo=23434. Acesso em: 15 jul. 2019. 


\section{A VIABILIDADE DE UTILIZAÇÃO DOS NAMING RIGHTS PELA ADMI- NISTRAÇÃO PÚBLICA BRASILEIRA COMO MEIO DE EXPLORAÇÃO ECONÔMICA DE BENS PÚBLICOS}

Nos Estados Unidos, local onde foi difundida a comercialização dos naming rights, passou a ocorrer a utilização dessa figura no setor público como uma alternativa à necessidade de captação de recursos do Estado. Ressalte-se a necessidade de observar a experiência norte-americana, considerando os seus aspectos positivos e negativos, de modo a evitar a reprodução de determinadas situações que podem prejudicar a instituição que cede o direito de denominação, especialmente no setor público.

A exploração econômica do espaço público tem como principal efeito direto o incremento na arrecadação, com baixos custos de transação. Ainda, os naming rights podem gerar alguns efeitos indiretos, sendo possível destacar a possibilidade de se efetuar a prestação de serviços de interesse coletivo de maneira mais ampla, eficiente e com melhor qualidade e a redução da carga fiscal da sociedade (ALMEIDA, 2013, p. 4-5).

Impende relembrar que a cessão onerosa dos naming rights não implica transferência da titularidade do bem. Assim, quando ocorre a cessão do direito de denominação de um bem público, este permanece sendo de propriedade do ente estatal, transferindo-se, temporariamente, apenas o direito à atribuição de denominação.

Com a disseminação da prática, passou-se a utilizá-la como alternativa arrecadatória de recursos do setor privado para o setor público. No âmbito da educação, escolas públicas norteamericanas no início do século XXI passaram a comercializar o direito de denominação, em razão de duas forças: a necessidade de dinheiro das escolas e a necessidade de publicidade dos negócios (BLOCHER, 2006, p. 2).

No contexto brasileiro, é possível perceber que existem demais negócios jurídicos semelhantes à cessão onerosa dos direitos de denominação de bens públicos. Diferencia-se este instituto, por exemplo, da adoção de espaço público, da nomeação honorífica e da doação com encargo de bens privados para a Administração Pública.

$\mathrm{Na}$ ambiência federal, a nomeação honorífica não pode homenagear indivíduos vivos. A Lei Federal $n^{\circ} 6.454 / 77$ proíbe a atribuição de nome de pessoa viva a bem público de qualquer natureza. ${ }^{8}$ Trata-se, portanto, de uma demonstração unilateral de reconhecimento, não havendo

8 Pelo que se deduz de sua literalidade, a Lei 6.454/77 não se aplica a entidades estaduais e municipais, à exceção das que recebam subvenção ou auxílio dos cofres públicos federais. É recomendável, porém, que sejam promulgadas leis análogas nas esferas estadual e municipal. Eis o seu teor: "Art. $1^{\circ}$ É proibido, em todo o território nacional, atribuir nome de pessoa viva ou que tenha se notabilizado pela defesa ou exploração de mão de obra escrava, em qualquer modalidade, a bem público, de qualquer natureza, pertencente à União ou às pessoas jurídicas da administração indireta. (Redação dada pela Lei ${ }^{\circ} 12.781$, de 2013)

Art. $2^{\circ}$ É igualmente vedada a inscrição dos nomes de autoridades ou administradores em placas indicadores de obras ou em veículo de propriedade ou a serviço da Administração Pública direta ou indireta.

Art. $3^{\circ}$ As proibições constantes desta Lei são aplicáveis às entidades que, a qualquer título, recebam subvenção ou auxílio dos cofres públicos federais.

Art. $4^{\circ} \mathrm{A}$ infração ao disposto nesta Lei acarretará aos responsáveis a perda do cargo ou função pública que exercerem, e, no caso do artigo $3^{\circ}$, a suspensão da subvenção ou auxílio." Invocando tal Lei e o art. $37, \S 1^{\circ}$, da CF/88, bem como os princípios da moralidade, impessoalidade e legalidade, o CNJ editou a Resolução 140/2011, proibindo a atribuição de nomes de pessoas vivas aos bens públicos "sob a administração de órgãos do Poder Judiciário", abrangendo, portanto, o Poder Judiciário estadual. Revogou ainda a Resolução CNJ 52/2008, que permitia a nomeação se "o homenageado for ex-integrante do Poder Público, e se encontre na inatividade, em face da aposentadoria decorrente de tempo de serviço ou por força da idade", mas preservou a validade das "atribuições de nomes firmadas até 29 de março de 2011" nos moldes da resolução revogada. 
contraprestação pecuniária em razão da nomeação, nem relação contratual. Não há confundi-la, portanto, com a cessão onerosa de naming rights. Nos EUA, todavia, é frequente, assinaladamente no âmbito universitário, que, em agradecimento a uma doação vultosa, a instituição espontaneamente resolva atribuir o nome do doador a prédio, sala, bolsa de estudos ou cátedra da referida instituição. No entanto, de último tem-se tornado mais comum a "doação filantrópica condicionada" e a comercialização dos naming rights, normalmente ofertados nos sítios eletrônicos de Universidades estadunidenses sob o apelo de "naming opportunities", por vezes acompanhadas de tabelas de valores, à maneira de uma lista de compras. ${ }^{9}$

A adoção de espaços públicos também não se confunde com a exploração de naming rights, embora ambas possuam em comum a ideia de desoneração da Administração Pública e de preservação do patrimônio público. Enquanto a cessão onerosa de direito de denominação permite a atribuição de nome a um bem público, a adoção comercial permite tão somente a colocação de placa ou símbolo do adotante no espaço adotado, em troca da conservação da área adotada. Destarte, o nome do espaço público permanece o mesmo. Ademais, a contraprestação feita pelo adotante não é pecuniária, mas sim em forma de serviço de conservação (SAMPAIO, 2017, p. 79-80).

Outrossim, a exploração econômica da atribuição de nome também se distingue da doação com encargo de um bem privado para a Administração Pública. Enquanto esta é irrevogável e possui natureza intuitu personae, a venda de naming rights deve ser realizada por prazo determinado a qualquer indivíduo que preencha os requisitos que forem estipulados para tal (IKENAGA, 2012, p. 86). ${ }^{10}$

Conforme estabelecido anteriormente, inúmeros são os benefícios para as empresas privadas que investem em bens públicos, em razão da sua alta potencialidade econômica e visibilidade, enquanto a Administração Pública apresenta a necessidade de encontrar novas formas de arrecadação de valores para que consiga cumprir com todos os seus encargos. Ademais, a cessão de naming rights não impede o uso normal do bem público, não trazendo nenhum prejuízo ou limitação ao serviço público eventualmente prestado no prédio público cujo direito de denominação foi cedido. Assim, por exemplo, a atribuição de um nome a um auditório ou sala de aula de Faculdade não embaraça em nada o uso regular do espaço pelos alunos, professores e visitantes, mas é fonte geratriz de receita para a respectiva Faculdade, que poderá melhorar as condições físicas do próprio bem ou investir na melhoria de outras instalações da Faculdade em benefício de seus usuários. Percebe-se então haver interesses relevantes para ambas as partes.

À vista desses benefícios mútuos, não se vislumbra, a princípio, nenhum óbice intransponível à celebração de contratos de naming rights sobre bens públicos, parecendo uma solução

9 "Universities and colleges have long been named after donors - think of Harvard, Yale, Brown, and many others. By today's standards, John Harvard would hardly get a bench named after him given the modesty of his gift of books for the library back in the 17th century. At least one institution, Rowan University of New Jersey, changed its name when someone made a large donation - the old title was Glassboro State College. Buildings have traditionally been named after people - distinguished scholars, visionary academic leaders, and recently, big donors. 'Old Main' and Bascom Hall are indicative of a bygone age when place and merit were recognized. Now we have the Gloria and Jake Smith Administration Pavilion and the McGinty Family Chemistry Center. Many schools give donor names to class and seminar rooms. More than one institution of higher education puts names on its chairs - the kind that one sits in rather than endowed professorships. Professorships have long been named for donors of endowments - but some of the donors who have put their names on chairs raise eyebrows - the FedEx chair and many others. No doubt there is an Enron chair still out there somewhere." (ALTBACH, 2005, p. 17). Cf. ainda: BURTON, 2008, p. 82 et seq.

${ }^{10}$ SAMPAIO $(2017$, p. 80-91; 178) admite, em caráter excepcional, a doação de bem particular à Administração Pública com o encargo de esta atribuir o nome indicado pelo doador (ao bem doado ou a outro bem público) desde que (a) haja impossibilidade de competição para doação do bem, hipótese em que a licitação seria inexigível, e (b) o direito de denominação possua valor proporcionalmente inferior ao do bem doado, a ponto de não desnaturar o encargo. 
simples para minimizar a escassez de recursos de organizações públicas e demonstrando ser uma eficiente forma de publicidade para as instituições privadas.

No que se refere às instituições de ensino, as escolas públicas brasileiras, em regra, apresentam condições de funcionamento deploráveis, de modo que a comercialização dos direitos de denominação pode contribuir para reverter esse quadro.

No contexto do ensino superior, a situação é mais favorável, porquanto as universidades federais brasileiras são mais bem estruturadas do que as instituições de educação básica, uma vez que são mantidas por verbas federais. Entretanto, ainda há necessidade de maior captação de recursos para o alcance de desempenho satisfatório na pesquisa e produção acadêmica.

Nessa perspectiva, o Ministério da Educação (MEC) anunciou o "Programa Universidades e Institutos Empreendedores e Inovadores - Future-se", que, por meio de lei ordinária, possibilitaria, dentre outras medidas, a cessão onerosa de direitos de denominação associados às universidades e institutos federais. As instituições que optarem por participar do programa ficarão autorizadas a conceder a pessoas físicas ou jurídicas o direito de nomear uma parte de um bem, móvel ou imóvel, de um local ou evento, em troca de compensação pecuniária ou "economicamente mensurável".

Eis, no que interessa, o teor do anteprojeto de lei, publicado no DOU em 03.01.2020 (seção 1, p. 1) e submetido a consulta pública até 24.01.2020:

Art. $3^{\circ}$ Para fins do disposto nesta Lei, considera-se: [...]

VI - contrato de concessão de direito de nomear (naming rights) - instrumento jurídico que confere à pessoa física ou jurídica o direito de nomear bem, evento ou local de propriedade da universidade ou do instituto federal, por meio de contraprestação de recursos financeiros ou não, desde que economicamente mensurável; [...]

Art. 22. As universidades e os institutos federais poderão celebrar contratos de concessão de direito de nomear, com pessoas físicas ou jurídicas, para a exploração econômica de nome ou de marca, em contraprestação de recursos financeiros ou não, desde que economicamente mensuráveis.

$\S 1^{\circ} \mathrm{O}$ contrato de concessão do direito de nomear poderá abranger uma parte ou a totalidade de bem, móvel ou imóvel, de local ou de evento.

$\S 2^{\circ}$ A celebração do contrato de concessão do direito de nomear será precedida de edital de chamamento público e o processo administrativo correspondente será instruído com a justificativa do preço.

$\S 3^{\circ}$ A superveniência de atos ou fatos que depreciem o nome ou a marca constitui hipótese de rescisão do contrato, sem ônus para a concedente, demonstrada a potencialidade de causar prejuízo à instituição e respeitados os princípios do contraditório e da ampla defesa.

$\S 4^{\circ}$ Insere-se no âmbito da autonomia universitária, prevista no art. 207 da Constituição, a imposição de regras e limites para a escolha do nome ou da marca e para a definição do prazo do contrato. ${ }^{11}$

O referido programa tem por finalidade o fortalecimento da autonomia administrativa e financeira das Instituições Federais de Ensino Superior - IFES, por meio de parceria com orga-

11 Texto com as manifestações oriundas da consulta pública disponível em: http://www.participa.br/future-se/anteprojeto-de-lei-que-institui-o-programa-universidades-e-institutos-empreendedores-e-inovadores-future-se. Acesso em: 29 fev. 2020. A redação final do Projeto de Lei enviado à Câmara dos Deputados (PL n. 3076/2020) reproduz textualmente, no seu art. 20, o teor do art. 22 do anteprojeto acima transcrito, com mera alteração da dicção do $\S 4^{\circ}$, que passou a ser a seguinte: “Art. 20. [...] $\S 4^{\circ}$ As universidades e os institutos federais poderão estabelecer regras e limites para a escolha do nome ou da marca e para a definição da duração do prazo do contrato." 
nizações sociais e do fomento à captação de recursos próprios. Todavia, a maior parte das universidades federais, a exemplo da de São Paulo (Unifesp), do Rio de Janeiro (UFRJ) e de Brasília (UnB), já havia decidido não aderir ao programa ou manifestado críticas severas ao programa (CAFARDO; MENGUE, 2019). Dentre os argumentos dos que rejeitam a proposta, sobressai a gestão dos recursos com a participação de Organizações Sociais, o que pressupõe diminuição da autonomia das instituições, gerando fragilidades e riscos para as instituições aderentes. A despeito da polêmica envolvendo o programa "Future-se", o tema específico dos naming rights não parece ser foco de resistência significativa.

De qualquer sorte, ao tratar de naming rights de bens públicos, determinados aspectos negativos não podem ser desconsiderados. Almeida (2013, p. 6) aponta como desvantagem a possibilidade de haver uma diminuição no valor moral atribuído ao espaço público, em virtude da diminuição, na perspectiva coletiva, da sensação de que o ambiente explorado é realmente público, o que pode esvaziá-lo daquilo que o torna interessante aos particulares potencialmente propensos à exploração: a existência de identidade e valores comunitários em torno do bem público.

Da mesma maneira que a aquisição de naming rights pode ser positiva para os investidores, que terão seus nomes associados a determinados espaços/bens públicos, estes passariam a agregar os valores das marcas. Vê-se a importância de estabelecer uma relação de coerência e harmonia entre as atividades públicas e privadas para que o contrato de cessão onerosa do direito de denominação faça sentido e de fato traga benefícios tanto para a Administração Pública, quanto para as empresas privadas.

Ikenaga (2012, p. 43) aponta, dentre os possíveis problemas oriundos da prática, eventual ofensa à ordem democrática, ausência de identificação do bem por parte da sociedade e eventos supervenientes não previstos. Sobre a eventual ofensa à ordem democrática, a autora afirma estar relacionada à ausência de transparência quanto aos critérios de escolha dos particulares. Tal preocupação é legítima, razão pela qual é necessário estabelecer critérios de transparência nas escolhas dos investidores, recorrendo a procedimento seletivo imparcial (licitação, chamamento público, etc.), assim como informar o montante exato investido em determinado bem. ${ }^{12}$

A cessão de naming rights, em especial quando se trata de bens públicos, deve atender ao critério de identificação por parte da sociedade em relação ao bem. Do contrário, poderá haver rejeição da população ao nome e consequente prejuízo à imagem da pessoa física ou jurídica que o atribuiu ao bem público. Em relação à legitimidade do ato administrativo que determina a

12 Exigindo, por via de regra, licitação: “Como regra, a licitação será obrigatória para promover a cessão onerosa de direito à denominação. Assim se passa porque a cessão onerosa do direito à denominação configura uma relação jurídica de cunho contratual. Trata-se de ceder em favor de um particular determinado a fruição de um benefício relacionado com um bem público (princípio da isonomia). A licitação deverá ser modelada pela licitação para delegação de competências. Ou seja, a hipótese examinada deve ser subordinada ao modelo licitatório da Lei $\mathrm{n}^{\circ}$ 8.987, antes do que àquele da Lei $n^{\circ}$ 8.666. Assim se passa porque a cessão do direito à denominação não configura um contrato de permuta entre Administração e particular. Não se trata de relação jurídica que verse sobre a realização de prestações recíprocas entre Administração Pública e particular. O particular será investido na faculdade de explorar uma potencialidade econômica de um bem público, mediante determinada remuneração. Essa modalidade contratual não se confunde nem com compra, nem com obra, nem com serviço. Está mais próxima à alienação (temporária) de uma faculdade de titularidade pública, o que justifica a submissão ao regime licitatório da concessão ou permissão de serviço público. No entanto, poderá configurar-se situação de inexigibilidade de licitação, quando se evidenciar a inviabilidade de competição. Essa é uma questão a ser examinada em face do caso concreto." (JUSTEN FILHO, 2015, p. 237). Admitindo chamamento público: "Quando o encargo publicitário for tal que exclua a possibilidade de outros possíveis donatários fazerem o mesmo, como um naming rights, placa publicitária exclusiva ou em posição evidentemente preferencial em algum bem público, é imperativo a realização de procedimento seletivo. Esse procedimento seletivo deve garantir os valores constitucionais que são a base do artigo 37, XXI, da CF e foram explicitados pelo artigo $2^{\circ}$, XII, da Lei $n^{\circ}$ 13.019/14. Não é a pura e simples existência do encargo na doação que atrai o chamamento público, mas apenas aquele excludente de que outros doadores façam o mesmo.” (BIM; FARIAS, 2018, p. 60). 
comercialização do direito de denominação de um bem público, apresenta-se razoável a realização de consulta pública aos administrados, conferindo maior aceitabilidade do negócio jurídico por parte da população.

No âmbito da Administração Pública, pautada pela persecução do interesse público, o cuidado com a escolha do investidor privado deve ser ainda maior, dado que, uma vez que uma empresa adquire o direito de nomeação de um espaço público, é inevitável que seja feita uma associação entre os dois, o que nem sempre gerará benefícios a ambas as partes. Ademais, determinados serviços públicos podem ser associados como sendo de iniciativa de uma empresa particular, causando confusão para os administrados que podem não compreender a questão do direito de denominação para fins exclusivamente publicitários.

Nesse sentido, Bartow (2007, p. 930) afirma que algumas marcas parecem perfeitamente contentes em permitir que os consumidores fiquem confusos sobre a associação entre as marcas e a identidade dos reais fornecedores de bens e serviços.

Ainda utilizando o exemplo das escolas públicas norte-americanas, questiona-se a aceitação de investidores cujas mensagens ou identidades não são compatíveis com instituições de ensino e/ou inapropriadas para crianças e adolescentes, portanto, devem ser evitadas, como marcas de refrigerante ou de bebidas alcoólicas. Da mesma maneira, é patente que um hospital não deve ser designado com o nome de uma indústria de cigarros.

Ocorre que, conforme lembra Blocher (2006, p. 3), rejeitar investidores indesejáveis pode não ser tão simples quanto parece, pois a recusa pode ser discutida em juízo sob o argumento de discriminação e de violação do disposto na Primeira Emenda da Constituição dos Estados Unidos, à consideração de que os naming rights configuram uma forma de "speech", embora a mensagem e seu emitente não sejam claros. ${ }^{13}$

Verifica-se, pois, a necessidade de serem estabelecidos critérios e limites para a venda dos direitos de denominação para que haja coerência e transparência em tais relações negociais, visto que os ganhos financeiros advindos do patrocínio não podem ser o único parâmetro utilizado para determinar quem será o patrocinador. Do contrário, corre-se o risco de desnaturar a essência dos bens públicos patrocinados.

A principal objeção à concessão de naming rights de bens públicos no Brasil consiste na suposta necessidade de prévia autorização legislativa. Não há disposição expressa na legislação brasileira que proíba ou permita a cessão onerosa do direito de denominação (de bens públicos ou privados), de modo que tal transação poderia ser interpretada como ofensa ao princípio da legalidade administrativa.

Segundo o princípio da legalidade, a Administração Pública só pode fazer o que a lei permite, enquanto no âmbito das relações entre os particulares, o princípio aplicável é o da autonomia da vontade, que lhes permite fazer tudo o que a lei não proíbe (DI PIETRO, 2017, p. 96).

\footnotetext{
13 "Experience in other areas of government sponsorship suggests that soft drink and candy companies are not the biggest threat. Other undesirable sponsors - including advocates of truly reprehensible political and social ideas-may be lurking, hoping, quite literally, to make a name for themselves through a school sponsorship deal. Unfortunately, simply saying 'no' to these sponsors may be more difficult than school boards expect. The selection of named sponsors raises concerns that can lead straight from the schoolhouse to the courthouse: Once a school has one named sponsor, other would-be sponsors may be able to claim a First Amendment right to participate, just as would-be speakers have a constitutional right to participate in other government-created forums. Unfortunately, very few school board policies are currently attuned to this First Amendment concern, leaving schools that turn down a sponsor's offer open to charges of viewpoint and content discrimination and the very real possibility that they will have to accept sponsors whose products or message they oppose." (BLOCHER, 2006, p. 1).
} 
Característico do Estado de Direito, o referido princípio, segundo Carvalho Filho (2019, p. 20), denota a relação entre a atividade legislativa e a de executar as leis (administração e jurisdição), de modo que somente é legítima a atividade do legislador público se estiver condizente com o disposto em lei.

De feito, a Administração Pública só pode fazer o que a lei permite, mas não é necessário que tal permissão seja sempre expressa, podendo, portanto, ser implícita, inferível mediante interpretação sistemática da legislação. Da mesma forma, a Administração não pode fazer aquilo que a lei proíbe, explícita ou implicitamente. Do contrário, a atuação administrativa ficaria excessivamente engessada ou paralisada.

Segundo Medauar (2018, p. 117), o princípio da legalidade traduz-se, de modo simples, na seguinte fórmula: "A Administração deve sujeitar-se às normas legais". ${ }^{14}$

Isto posto, questiona-se acerca da possibilidade de utilização de um instituto por parte da Administração Pública que não está expressamente autorizado por lei. Justen Filho (2015, p. 236) sustenta, acertadamente, que a cessão onerosa de naming rights de bens públicos prescinde de autorização legislativa específica, de modo que a autorização legislativa genérica que permite ao Estado celebrar contratos administrativos compreende também a cessão do direito à denominação.

Não se trata de sobrepor o princípio da eficiência ao da legalidade - até porque este (princípio da legalidade) possui estrutura e natureza de norma-regra e aquele (princípio da eficiência) possui estrutura e natureza de norma-princípio, de modo que, ainda que se admita a ponderação entre ambos, dificilmente a norma principiológica sobrepujaria a norma-regra mais específica de igual estatura hierárquica. ${ }^{15}$ Cuida-se, em vez disso, de reconhecer os limites imanentes ao próprio princípio da legalidade administrativa.

Contudo, a ausência de regulamentação legal acerca dos naming rights de bens públicos pode fomentar insegurança jurídica, sendo recomendável a edição de lei apontando critérios bem

14 "Tornaram-se clássicos os quatro significados arrolados pelo francês Eisenmann: a) a Administração pode realizar todos os atos e medidas que não sejam contrários à lei; b) a Administração só pode editar atos ou medidas que uma norma autoriza; c) somente são permitidos atos cujo conteúdo seja conforme a um esquema abstrato fixado por norma legislativa; d) a Administração só pode realizar atos ou medidas que a lei ordena fazer. [...] O último significado - a Administração só pode realizar atos ou medidas que a lei ordena -, se predominasse como significado geral do princípio da legalidade, paralisaria a Administração, porque seria necessário um comando legal específico para cada ato ou medida editados pela Administração, o que é inviável. [...] O terceiro significado - somente são permitidos atos cujo conteúdo seja conforme a uma hipótese abstrata fixada explicitamente por norma legislativa - traduz uma concepção rígida do princípio da legalidade e corresponde à ideia de Administração somente executora da lei. Hoje não mais se pode conceber que a Administração tenha só esse encargo. Esse significado do princípio da legalidade não predomina na maioria das atividades administrativas, embora no exercício do poder vinculado possa haver decisões similares a atos concretizadores de hipóteses normativas abstratas." (MEDAUAR, 2018, p. 118).

${ }^{15}$ Em casos excepcionais, é possível que uma norma-princípio prevaleça sobre norma-regra de igual status hierárquico. Nesse sentido: "A partir de Herbert Hart, porção considerável da doutrina passou a reconhecer a derrotabilidade' ('defeasibility', 'derrotabilidad', 'deffetibilità') ou 'superabilidade' de normas-regras em situações extraordinárias nas quais haja razões suficientemente fortes para deixar de aplicá-las mesmo quando preenchidos os pressupostos fáticos da sua hipótese de incidência. Assim, é possível deixar de aplicá-las em razão de exceções implícitas (ad hoc), imprevisíveis, imprevistas ou deficientemente previstas pelo legislador, decorrentes (a) da própria teleologia da norma-regra (rule's purpose) ou da interpretação (c) de normas-princípios ou (b) de outras normas-regras. Portanto, ainda que atendidos os pressupostos fáticos do antecedente do normativo e observados os degraus da 'escada ponteana' (planos de existência, validade e eficácia), é possível que o resultado previsto abstratamente no consequente normativo não seja efetivamente aplicado, nem deva sê-lo, por incidir uma exceção implícita extraordinária ('dado o fato X, deve ser a sanção Y, exceto na situação Z'). Embora a norma-regra seja aplicável em abstrato, não deve sê-lo no caso concreto excepcional. Mas a norma-regra continua existente, válida, vigente, eficaz e aplicável em abstrato, não perdendo sua força normativa, nem sendo derrogada em sentido estrito. Esses casos concretos excepcionais normalmente são insuscetíveis de prévia enumeração exaustiva." (FERNANDES, 2020, p. 263-264). 
definidos para evitar desvios na funcionalidade do bem público e para atender às reais necessidades dos administrados.

\section{CONSIDERAÇÕES FINAIS}

O presente texto teve como finalidade analisar a exploração econômica de bens públicos por meio de naming rights, abordando a questão do gerenciamento de bens públicos e o princípio da eficiência, e investigando a compatibilidade do referido instituto com o ordenamento jurídico brasileiro.

Percebe-se que ainda há um longo percurso a ser trilhado até a consolidação da cessão onerosa do direito de denominação de bens públicos no Brasil, sendo necessária uma mudança de postura dos administradores. A ausência de autorização legal expressa não é empecilho à celebração de contratos de cessão onerosa de naming rights de bens públicos, uma vez que se trata de contrato atípico, emanação da autonomia contratual da Administração Pública. Com efeito, a vetusta concepção do princípio da legalidade, no sentido de que "a Administração só pode fazer o que a lei expressamente prevê", além de irreal, já se encontra superada pela doutrina administrativista mais moderna. Portanto, à sombra da definição contemporânea do princípio da legalidade, nada obsta, de jure condito, à celebração de contratos onerosos de naming rights pela Administração Pública brasileira.

Entretanto, força é reconhecer a conveniência de uma disciplina legal do instituto, a fim de conferir mais segurança jurídica a tais transações, reduzindo a probabilidade de questionamentos judiciais e dos custos daí advenientes, e, por consequência, expandindo o universo de potenciais interessados e elevando os valores ofertados.

Analisando a cessão onerosa de naming rights como instrumento de arrecadação e efetivação de direitos humanos da população, verifica-se que os bens públicos podem ser objeto de negócio jurídico envolvendo a comercialização do seu direito de denominação, assim como ocorre com os bens no âmbito privado. Contudo, vê-se inevitável a associação entre o bem e o investidor, razão pela qual cumpre sejam estabelecidos critérios bem definidos para escolha dos investidores e que o interesse dos administrados seja contemplado, conferindo legitimidade à transação.

Em síntese, é válida e legítima a cessão onerosa de naming rights de bens públicos, desde que observados alguns pressupostos e requisitos mínimos, a saber: a) duração temporária do contrato; b) existência de procedimento seletivo (licitação, chamamento público, consulta popular, etc.) que assegure isonomia de tratamento entre os potenciais interessados e transparência nos critérios de escolha, que não podem circunscrever-se ao valor ofertado; c) adequação do nome (respeitabilidade, congruência com os valores constitucionais e da instituição a que pertence o bem nomeado, etc.); d) previsão de rescindibilidade do contrato em caso de fatos supervenientes (ou supervenientemente conhecidos) que abalem a respeitabilidade ou a credibilidade do nome atribuído; e) vinculação do total dos valores auferidos à instituição a que pertence o bem, preferencialmente destinados à melhoria do próprio bem, interditado o desvio de tais recursos para satisfação de objetivos e encargos de outras instituições públicas, ainda que a pretexto de atendimento do "interesse público"; e f) moderação na concessão de naming rights, evitando abusos capazes de desequilibrar o trade-off entre a necessidade de recursos e a percepção social de privatização completa dos bens públicos. 
Ademais, nem todos os bens públicos podem ser objeto de naming rights: bens de alto valor histórico ou identitário comum, tais como o Cristo Redentor, o Corcovado e a Praia de Copacabana, são insuscetíveis de renomeação mediante contratos de naming rights.

Todavia, em havendo possibilidade jurídica de comercialização dos direitos de denominação como uma alternativa à escassez de recursos, o Estado possui a responsabilidade, designadamente à luz dos princípios da eficiência, do interesse público e da função social da propriedade, de valer-se de tal possibilidade, com prudência e sobriedade, como meio de assegurar a boa qualidade do serviço público e os demais direitos fundamentais, a exemplo do que ocorre nos países que permitem a comercialização de naming rights de bens públicos.

\section{REFERÊNCIAS}

ALMEIDA, Luís Felipe Sampaio. Exploração de naming rights de bens públicos no direito comparado. In: XXXIX Congresso Nacional dos Procuradores do Estado. Porto de Galinhas, 2013.

ALTBACH, Philip. G. What's in a Name? How Universities Sow Confusion and Cheapen Academe. International Higher Education, n. 40, Summer 2005. DOI: https://doi.org/10.6017/ ihe.2005.40.7483.

BARTOW, Ann. Trademarks of privilege: Naming Rights and the Physical Public Domain. UC Davis Law Review, v. 40, n. 3, p. 919-970, mar. 2007.

BIM, Eduardo Fortunato; FARIAS, Talden. Da validade da doação à Administração Pública: do Estado donatário. A\&C - Revista de Direito Administrativo \& Constitucional, Belo Horizonte, ano 18, n. 72, p. 51-69, abr./jun. 2018.

BLOCHER, Joseph. Selling the Name on the Schoolhouse Gate: the First Amendment and the Sale of Public School naming rights. School Law Bulletin. School of Government, The University of North Carolina at Chapel Hill, 2006.

BURTON, Terry. Naming rights: legacy gifts and corporate money. Hoboken, NJ: John Wiley \& Sons, 2008.

CAFARDO, Renata; MENGUE, Priscila. Maioria das universidades federais rejeita Future-se, do MEC. Terra, São Paulo, Educação, 26 set. 2019. Disponível em: https://www.terra.com.br/ noticias/educacao/maioria-das-universidades-federais-rejeita-future-se-domec,a7e20ebe75c822883e8082cbb1f5ac010q77aekd.html. Acesso em: 29 set. 2019.

CARVALHO FILHO, José dos Santos. Manual de direito administrativo. 33. ed. São Paulo: Atlas, 2019.

DI PIETRO, Maria Sylvia Zanella. Direito administrativo. 30. ed. Rio de Janeiro: Forense, 2017.

FERNANDES, André Dias. Corte de energia elétrica e derrotabilidade normativa: necessidade de diálogo entre o Código de Defesa do Consumidor, o Código de Defesa do Usuário de Serviços Públicos e a Constituição. Revista de Direito do Consumidor, v. 127, p. 249-276, jan./fev. 2020. 
HALLIGAN, Neil. Dubai Arena signs ten-year naming rights deal with Coca-Cola. Arabian Business, Dubai, Industries, Travel \& Hospitality, 8 apr. 2019. Disponível em: https://www.arabianbusiness.com/travel-hospitality/417276-dubai-arena-signs-ten-year-naming-rights-dealwith-coca-cola. Acesso em: 12 jul. 2019.

HENDERSON, David R. Opportunity cost. The library of economics and liberty, Carmel, Concise Enciclopedia of Economics, 12 abr. 2006. Disponível em: http://www.econlib.org/library/Enc/OpportunityCost.html. Acesso em: 2 mar. 2020.

HOSS, Osni. Modelo Hoss de Avaliação de Ativos Intangíveis; CAP Accounting and Management, v. 2, n. 2, 2008. Disponível em: revistas.utfpr.edu.br. Acesso em: 15 jul. 2019.

IKENAGA, Ana Lúcia. A atribuição de nome como modo de exploração de bens públicos. Dissertação (Mestrado em Direito do Estado) - Faculdade de Direito, Universidade de São Paulo, São Paulo, 2012.

ISIDORE, Chris. Astros strike out Enron. CNN Money, New York, News, Companies, 27 feb. 2002. Disponível em: https://money.cnn.com/2002/02/27/companies/enron_astros/. Acesso em: 23 jul. 2019.

JORNAL CONTÁBIL. Os 9 maiores escândalos contábeis do mundo. Rede Jornal Contábil, Araguari, MG, 21 jul. 2018. Disponível em: https://www.jornalcontabil.com.br/os-9-maioresescandalos-contabeis-do-mundo/. Acesso em: 23 jul. 2019.

JUSTEN FILHO, Marçal. A exploração econômica de bens públicos: cessão do direito à denominação. In: GUERRA, Sérgio; FERREIRA JUNIOR, Celso Rodrigues (coord.). Direito administrativo: estudos em homenagem ao professor Marcos Juruena Villela Souto. Belo Horizonte: Fórum, 2015, p. 221-238.

LIPOVETSKY, Gilles. Les temps hypermodernes. Paris: Grasset, 2004.

MEDAUAR, Odete. Direito administrativo moderno. 21. ed. Belo Horizonte: Fórum, 2018.

SCHIRATO, Victor Rhein. A noção de serviço público em regime de competição. Tese (Doutorado em Direito do Estado) - Faculdade de Direito, Universidade de São Paulo, São Paulo, 2011. Disponível em: www.teses.usp.br/teses/disponiveis/2/2134/tde.../Tese Vitor_Rhein Schirato_Final.pdf. Acesso em: 09 jul. 2019.

SAMPAIO, Luís Felipe. Naming Rights de Bens Públicos. São Paulo: Almedina, 2017.

SECCHI, Leonardo. Modelos organizacionais e reformas da administração pública. Revista de Administração Pública, 43(2): 347-69, mar/abr. 2009.

TREX, Ethan. A Brief History of Stadium Naming Rights. Mental Floss, New York, Sports, 27 nov. 2008. Disponível em: https://www.mentalfloss.com/article/20239/brief-history-stadiumnaming-rights. Acesso em: 15 jul. 2019.

URBANO, Fabiano Augusto Rodrigues. Naming Rights: Receita adicional para o Centro de Convenções de Pirituba. 2013. 25f. Artigo (Mestrado) - Escola de Administração de Empresas de São Paulo, Fundação Getúlio Vargas, 2013. Disponível em: http://bibliotecadigital.fgv.br/ dspace/bitstream/handle/10438/11191/Trabalhoindividual\%20-\%20naming\%20rights.pdf?sequence=1. Acesso em: 19 jul. 2019.

Recebido em: 2 mar. 2020.

Aceito em: 13 out. 2020. 